\title{
Bilateral Chronic Subdural Nontraumatic Hematoma in a Woman Affected by AL Amyloidosis
}

\author{
$\begin{array}{lll}\text { M. Luongo } & & \text { M. Grassi } \\ & & \text { U. Godano }\end{array}$ \\ ${ }^{1}$ Department of Neurosurgery, San Carlo Hospital, Potenza, Italy \\ J Neurol Surg Rep 2015;76:e164-e166.
}

\begin{abstract}
Address for correspondence Marianna Luongo, MD, Department of Neurosurgery, "San Carlo" Hospital, via Potito Petrone - 85100, Potenza, Italy (e-mail: marianna.luongo@gmail.com).
\end{abstract}

\begin{abstract} Keywords

- chronic subdural hematoma

- AL amyloidosis

- headache

- acute subdural bleeding

- amyloids

- vessel fragility

Chronic subdural hematoma (CSDH) is a condition frequently seen in neurosurgical practice, especially among the elderly. It is often preceded by head injury, even a trivial trauma. Light chain (AL) amyloidosis is a disorder involving extracellular tissue deposition of misfolded native proteins called amyloids. The several types of amyloidosis differ by source of proteins, organ involvement, treatment, and prognosis. We describe the case of a 59-year-old woman affected by AL amyloidosis, harboring surgically treated bilateral chronic nontraumatic subdural hematoma, and we suggest a possible correlation between the clinical entities of CSDH and AL amyloidosis.
\end{abstract}

\section{Introduction}

Chronic subdural hematoma (CSDH) is a clinical entity seen very frequently in neurosurgery, especially among the elderly. Sometimes this pathology affects people younger than the mean age without the so-called classical risk factors, and in such situations, it could have been related to other pathologic conditions such as coagulopathies. Light chain (AL) amyloidosis is the most frequent type of amyloidosis, but it is often misdiagnosed because of its initial symptoms that can mimic other pathologies (neoplasms, infections, and inflammations). The annual incidence of AL amyloidosis is 5.1-12.8 million people in the United States, and considering that it rarely involves the central nervous system, it is plausible to think that more cases are associated with CSDH, due to a vascular fragility determined by the deposition of amyloid fibrils.

\section{Material and Methods}

A 59-year-old woman affected by AL amyloidosis was diagnosed in 2008. Her condition was characterized by salivary lymphadenopathy without macroglossia, a sideropenic anemia due to gastrointestinal involvement, and a pulmonary interstitiopathy without neurologic, hepatic, renal, or cardiac failure. After being treated initially by chemiotherapy with rituximab, fludarabine, and cyclophosphamide, she was also treated with cyclophosphamide, dexamethasone, and rituximab, which had led to a stable situation since August 2011.

In January 2013, the patient presented with a continuous headache and weakness in her legs, with no previous head injury or history of bleeding disorders. A computed tomography (CT) scan showed a bilateral hypodense signal, referring to a chronic collection of blood, so prompt bilateral burr holes were performed, positioning close subdural drainage that was removed 48 hours later ( - Fig. 1). Seven days after surgery, worsening clinical conditions (headache followed by a comatose state) and another CT scan showing the presence of acute subdural bleeding at the left frontoparietal side, associated with a 14-mm-thick pneumocephalus, determined the need for another surgical evacuation, through the same hole, on the left side (-Fig. 2).

Once the second surgical procedure was performed, the improved clinical conditions allowed the patient to be discharged, symptom free, 13 days later.
License terms

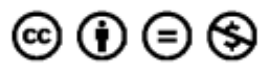

received

March 18, 2015

accepted

March 28, 2015

published online

June 26, 2015
DOI http://dx.doi.org/

$10.1055 / \mathrm{s}-0035-1554933$.

ISSN 2193-6366. (c) 2015 Georg Thieme Verlag KG Stuttgart · New York 

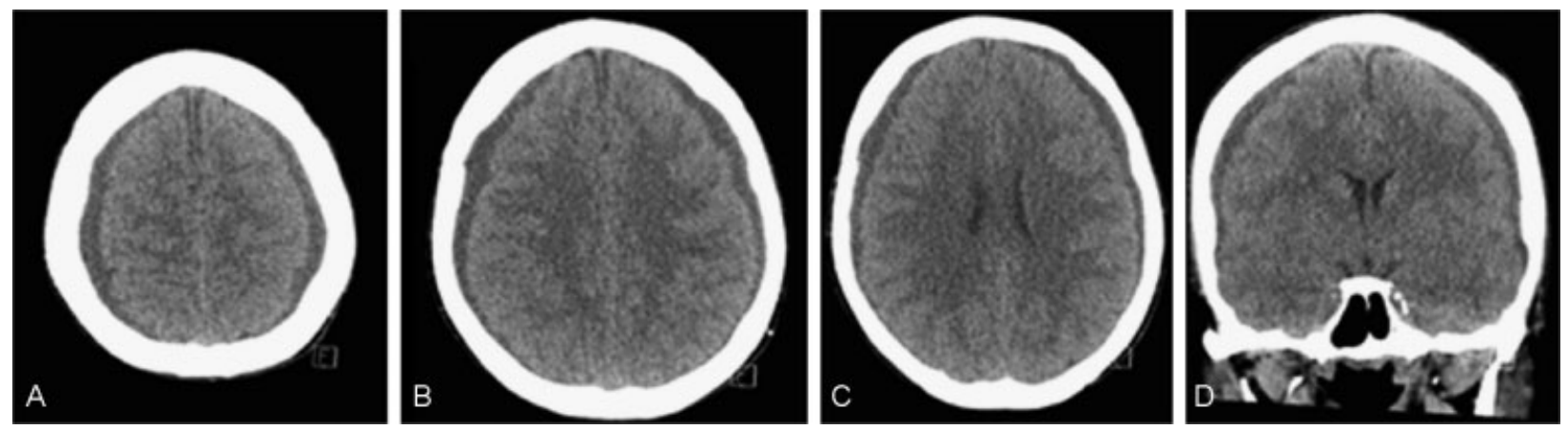

Fig. 1 (A-D) Preoperative computed tomography scan showing bilateral chronic subdural hematoma.

\section{Discussion}

The incidence of CSDH in neurosurgery is 1 to 5.3 cases per 100,000 per year, and 7.4 per 100,000 among the elderly. It often follows a trivial head injury, and its development is provoked by specific conditions (e.g., arterial hypertension, cardiovascular disease, coagulopathies, diabetes, anticoagulant and antiaggregant therapy, chronic alcoholism). Nontraumatic causes are rare.

AL amyloidosis is a disorder characterized by the excessive clonal production by plasma cells in the bone marrow of immunoglobulin light chains (LCs) that subsequently misfold, aggregate, and leave sediment in tissues as amyloid fibrils. It is considered a rare disease, but with an incidence of 0.8 cases per 100,000 per year, it is likely the diagnosis of LC amyloidosis will increase. ${ }^{1}$ The clear pathologic mechanism is not completely known, but the deposition of amyloid proteins in the extracellular and perivascular spaces in organs such as the heart, liver, gastrointestinal tract, kidneys, and peripheral nerves is associated with apoptosis, injury, and oxidative stress. Perivascular deposition and tissue damage have been correlated, and evidence from cell culture studies suggest that even circulating amyloidogenic LCs may cause direct tissue injury. ${ }^{2}$ The systemic form of AL amyloidosis predominantly affects the gastrointestinal system (liver and intestines), kidneys, and peripheral nerves; cardiac involvement and heart failure suggest the worst prognosis.
We described the case of a woman affected by AL amyloidosis harboring a bilateral nontraumatic CSDH. To the best of our knowledge no other cases have ever been described.

The patient showed neither so-called classical risk factors for CSDH nor a history of head injury, neurosurgical intervention, or bleeding disorders, and she was not on any medications that could cause coagulopathy. She had been affected by LC systemic amyloidosis since 2008, presenting an unusual manifestation with no cardiac involvement, a good response to chemotherapy, and an absence of symptoms since August 2011.

She was submitted to a burr hole craniostomy to evacuate a bilateral chronic subdural nontraumatic hematoma, with clinical signs of a continuous headache with weakness in both legs. Her blood work and specifically platelets counts were normal, as well as prothrombin time (PT) and activated partial thromboplastin time (aPTT). She only had sideropenic anemia, due to the well-known gastrointestinal involvement by amyloidosis ( - Table $\mathbf{1}$ ).

After an initial good postoperative recovery, the patient had a sudden headache followed by a comatose state. The CT scan revealed the presence of acute subdural bleeding on the left side. The complication was promptly treated surgically through the same burr hole and by positioning a closed drainage system, associated with a significantly lower secondary recurrence. ${ }^{3}$ The postoperative course was routine, and the patient was discharged symptom
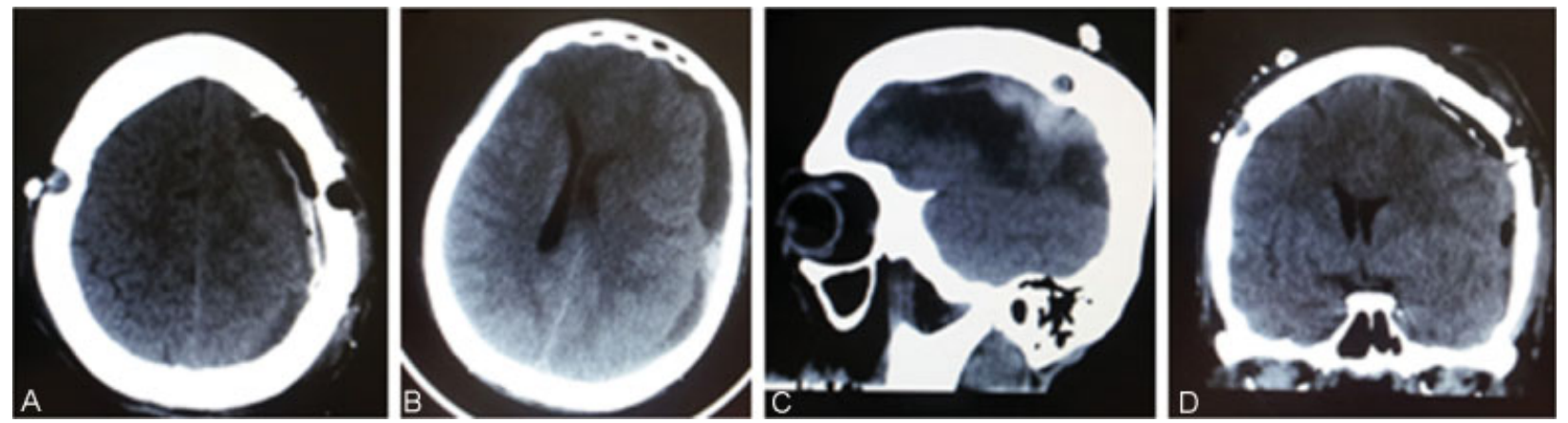

Fig. 2 (A-D) Postoperative computed tomography scan showing the presence of an acute subdural hematoma on the left. In (C), a detail of the sagittal section shows the depth of the left acute subdural hematoma. In (D), the left frontoparietal burr hole is visible. 
Table 1 Platelet counts and coagulation values

\begin{tabular}{|l|l|l|l|l|l|}
\hline & $\begin{array}{l}\text { Preoperative } \\
\text { Bilateral chronic } \\
\text { subdural } \\
\text { hematoma } \\
\text { evacuation }\end{array}$ & $\begin{array}{l}\text { Postoperative } \\
\text { Bilateral chronic } \\
\text { subdural } \\
\text { hematoma } \\
\text { evacuation }\end{array}$ & $\begin{array}{l}\text { Postoperative } \\
\text { Acute subdural } \\
\text { hematoma } \\
\text { evacuation }\end{array}$ & $\begin{array}{l}\text { Normal } \\
\text { values }\end{array}$ & Unit of measures \\
\hline Platelet & 253 & 253 & 253 & $150-400$ & Giga/L \\
\hline Mean platelet volume & 9.30 & 8.60 & 8.60 & - & $\mu m^{3}$ \\
\hline aPTT & 34.4 & 32.3 & - & Seconds & Seconds \\
\hline PT & 12.7 & 13.1 & - & $>70$ & $\%$ \\
\hline Prothrombin activity percentage & 121 & 112 & - & $0.80-1.20$ & \\
\hline INR & 0.90 & 0.94 & - & \\
\hline
\end{tabular}

Abbreviations: aPTT, activated partial thromboplastin time; INR, international normalized ratio; PT, prothrombin time.

free after 13 days, with a CT showing an improvement of her brain condition.

The prognosis of AL amyloidosis manifesting as lymphadenopathy is usually good, as long as there are no hematologic malignancies or rapid increases in the size of lymph nodes. ${ }^{4}$ Hemorrhage is a frequent manifestation, and although mild intracutaneous bleeding is the most common, cases of life-threatening hemorrhage are well described. ${ }^{5,6}$ These patients may present widespread fragility of the small vessels as a direct result of amyloid infiltration, and the risk of bleeding can be exacerbated by a variety of coagulation abnormalities. $^{7,8}$

Mumford and colleagues analyzed 337 patients affected by AL amyloidosis focusing on bleeding symptoms and coagulation abnormalities. They found that the coagulation screen was abnormal in $51 \%$ of cases with prolongation of the thrombin time in $32 \%$ and PT in $24 \%{ }^{9}$ Veneri et al, apart from capillary fragility, affirmed that hemorrhagic signs could be related to an acquired deficiency of clotting factor $\mathrm{X}$ that leads to prolongation of PT and aPTT. ${ }^{10}$ Wettlé et al asserted that hemorrhagic manifestations of systemic amyloidosis can be secondary to acquired factor $\mathrm{X}$ deficiency, but also to capillary fragility due to the infiltration of amyloid fibrils in the vessel walls. ${ }^{8}$

We previously described three cases of patients presenting nontraumatic CSDH affected by von Willebrand type I disease, ${ }^{11,12}$ and so we verified the absence of this condition.

The case history presented here provoked our thinking about a prospective relationship between CSDH and $\mathrm{AL}$ amyloidosis because of the absence of other risk factors (such as coagulopathies, trauma, or medications) that could justify a physiopathologic developing mechanism for CSDH or coagulation factor deficiency. ${ }^{13}$

We suggest the hypothesis of a possible direct vascular injury due to the infiltration of LCs in the cerebral vessel walls, given that nervous system AL amyloidosis involvement just involves peripheral and autonomic neuropathy, but, at the time, no other correlations had been described.

The vascular fragility determined by amyloid deposits ${ }^{8}$ could also explain the rapid occurrence of complications in our case, despite careful postoperative management and the absence of coagulation abnormalities. It could also be considered a predisposing factor for a prospective recurrence. ${ }^{2}$

\section{Conclusion}

Further evidence, even deriving from autopsy studies, are needed to clearly demonstrate this association to better manage such a common neurosurgical disease affecting these frail patients, although the low incidence of AL amyloidosis could make this correlation more difficult to identify.

\section{References}

1 Kyle RA, Linos A, Beard CM, et al. Incidence and natural history of primary systemic amyloidosis in Olmsted County, Minnesota, 1950 through 1989. Blood 1992;79(7):1817-1822

2 Merlini G, Bellotti V. Molecular mechanisms of amyloidosis. N Engl J Med 2003;349(6):583-596

3 Penchet G, Loiseau H, Castel JP. Chronic bilateral subdural hematomas [in French]. Neurochirurgie 1998;44(4):247-252

4 Matsuda M, GonoT, Shimojima Y, et al. AL amyloidosis manifesting as systemic lymphadenopathy. Amyloid 2008;15(2):117-124

5 Kyle RA, Greipp PR. Amyloidosis (AL). Clinical and laboratory features in 229 cases. Mayo Clin Proc 1983;58(10):665-683

6 Yood RA, Skinner M, Rubinow A, Talarico L, Cohen AS. Bleeding manifestations in 100 patients with amyloidosis. JAMA 1983; 249(10):1322-1324

7 Greipp PR, Kyle RA, Bowie EJ. Factor-X deficiency in amyloidosis: a critical review. Am J Hematol 1981;11(4):443-450

8 Wettlé C, Springinsfeld G, Lipsker D. Haemorrhage and amyloidosis-response to Veneri et al. Br J Haematol 2013;160(6):854-855

9 Mumford AD, O'Donnell J, Gillmore JD, Manning RA, Hawkins PN, Laffan M. Bleeding symptoms and coagulation abnormalities in 337 patients with AL-amyloidosis. Br J Haematol 2000;110(2):454-460

10 Veneri D, Pizzolo G, Bonalumi A, Franchini M. Haemorrhage and amyloidosis. Br J Haematol 2013;160(6):854

11 Luongo M, Pizzuti M, Godano U. Bilateral chronic subdural nontraumatic hematoma associated with von Willebrand's type I disease: a case report. Acta Neurochir (Wien) 2012;154(6):1087-1088

12 Luongo M, Pizzuti M, Godano U. Chronic subdural non traumatic hematoma associated with von Willebrand's disease: a real clinical association or just a mere coincidence? Clin Neurol Neurosurg 2013;115(8):1569-1570

13 Manikkan AT. Factor X deficiency: an uncommon presentation of AL amyloidosis. Ups J Med Sci 2012;117(4):457-459 